\title{
Neutrophil-Lymphocyte Ratio Predicts Overall Survival in Elderly Patients With Unresectable or Recurrent Gastric Cancer
}

\author{
Yoshiya Yamauchi \\ Tokyo Medical University \\ Atsushi Sofuni \\ Tokyo Medical University \\ Yuka Suzuki \\ Tokyo Medical University \\ Takashi Kurosawa \\ Tokyo Medical University \\ Kenichi Iwasaki \\ Tokyo Medical University \\ Akihiko Tsuchida \\ Tokyo Medical University \\ Takao Itoi ( $\nabla$ itoitakao@gmail.com ) \\ Tokyo Medical University
}

\section{Research Article}

Keywords: Elderly, neutrophil-lymphocyte ratio, platelet-lymphocyte ratio, Glasgow prognostic score, gastric cancer, prognosis

Posted Date: May 19th, 2021

DOI: https://doi.org/10.21203/rs.3.rs-512528/v1

License: (c) (1) This work is licensed under a Creative Commons Attribution 4.0 International License. Read Full License 


\section{Abstract}

\section{Background}

The relationship between various systemic inflammatory biomarkers and outcomes in patients with a variety of solid cancers has been reported. However, the relevance of these markers is unclear in elderly patients with unresectable or recurrent gastric cancer (GC). This retrospective study was conducted to identify specific factors associated with the survival of elderly patients with GC.

\section{Methods}

Patients with GC undergoing chemotherapy at our institution from April 2014 to April 2020 were included in the study. The patients were categorized into either the young group ( $Y$ group; aged $<70$ years) or the elderly group ( $E$ group; aged $\geq 70$ years). The association between overall survival (OS) and pre-treatment values of systemic biomarkers, including the neutrophil-lymphocyte ratio (NLR), platelet-lymphocyte ratio, and Glasgow prognostic score, was evaluated using the Kaplan-Meier method and log-rank test in each group. Univariate and multivariate analyses using Cox proportional hazards regression were used to investigate the prognostic factors associated with OS in each group.

\section{Results}

A total of 112 patients were eligible for inclusion in the analysis. The patients were categorized into the $Y$ and $E$ groups based on their age, and each group consisted of 56 patients. In both groups, high NLR and high Glasgow prognostic score were associated with poor OS (Y: $p=0.002$ and $p=0.009 ; \mathrm{E}: p<0.001$ and $p=0.045$, respectively), whereas the platelet-lymphocyte ratio was not ( $\mathrm{Y}: p=0.296 ; \mathrm{E}: p=0.346)$. Univariate and multivariate Cox regression analyses revealed that poor performance status was correlated with poor OS in the Y group (hazard ratio: 2.56; 95\% confidence interval: $1.02-6.43 ; p=0.045$ ). However, in the E group, NLR was the only independent prognostic factor of OS (hazard ratio: $4.22 ; 95 \%$ confidence interval: $1.69-10.56 ; p=0.002$ ).

\section{Conclusions}

Poor performance status was an independent marker of poor prognosis in the $Y$ group, whereas a high NLR was an independent marker in the E group. Thus, NLR may be a specific biomarker for predicting the OS of elderly patients with unresectable GC.

\section{Background}

Gastric cancer (GC) is one of the most common malignant tumors of the digestive system and is the fifth most common type of cancer and the third leading cause of cancer-related deaths [1]. Most patients with GC are elderly; it is estimated that patients aged 65 years or older account for approximately $70 \%$ of the total cases of GC [2]. Consequently, the number of elderly patients with advanced GC has increased because of general population aging and increased life expectancy [3]. There is widespread concern 
regarding the ability of elderly patients to tolerate chemotherapy, given their higher likelihood of frailty and multiple comorbidities. This may result in chemotherapy not being offered, or the planned treatment being modified or stopped early, with potentially negative prognostic implications. Generally, chemotherapy is chosen based on the patient's overall health, including their performance status (PS), organ function, and the presence of comorbidities. The PS defined by the Eastern Cooperative Oncology Group (ECOG) is an important factor associated with patient clinical outcomes and is useful for determining the indication of chemotherapy in patients with cancer [4,5]. However, these factors are considered to be less reliable in the elderly than in younger individuals because of the physical, psychological, and social complexities concerning elderly patients [6]. Thus, it is important to identify the markers that can predict clinical outcomes in elderly patients.

Recently, many studies have identified an association between systematic inflammation and cancer progression. Furthermore, several studies suggested that some routine blood biomarkers such as the neutrophil-lymphocyte ratio (NLR), platelet-lymphocyte ratio (PLR), and Glasgow prognostic score (GPS), can help in evaluating the clinical outcomes of patients with cancer [7-12]. These parameters may be useful as practical biomarkers in routine practice. However, the prognostic value of these biomarkers for elderly patients remains uncertain, as most studies of inflammatory biomarkers were performed on young individuals, and few studies have exclusively included the elderly. Thus, in the present study, we investigated the specific factors affecting the overall survival (OS) of elderly patients with unresectable GC.

\section{Methods}

\section{Patients and study design}

This retrospective study included patients with unresectable or recurrent GC who were treated with chemotherapy from January 2014 to April 2020 at our institution. All diagnoses were based on pathological confirmation, and the patients' medical records were reviewed. The patients were divided into two groups based on their age: the young $(Y)$ group included patients under 70 years of age and the elderly (E) group comprised patients aged 70 years and above. The exclusion criteria were as follows: insufficient information and did not undergo chemotherapy at our institution.

\section{Inflammatory biomarker evaluation}

Data were collected before the commencement of chemotherapy, which included patient demographics, tumor localization, complete blood count, serum albumin level $(\mathrm{g} / \mathrm{dL})$, C-reactive protein level $(\mathrm{mg} / \mathrm{dL})$, blood count, and other clinicopathological parameters.

NLR, PLR, and GPS were evaluated as biomarkers of inflammation. GPS was determined according to the following scoring system: patients with both increased C-reactive protein (>1.0 mg/dL) and hypoalbuminemia $(<3.5 \mathrm{~g} / \mathrm{dL})$ received a score of 2 , whereas those satisfying only one of these criteria received a score of 1 , and those with neither of these findings received a score of 0 . Because of the 
relatively small number of patients, the optimal cutoff value was not determined by a receiver operating characteristic curve. Rather, the cutoff value for each parameter was determined as per previous reports.

The cutoff values of NLR $=4$, set by Shimada et al. [13], and PLR $=150$, set by Song et al. [14], were used, and a GPS score of 1 or 2 was regarded as high.

\section{Statistical analysis}

OS was defined as the interval from the initiation of treatment until death. Patients who were still alive were censored at the final follow-up.

The $Y$ and $E$ groups were compared by Student's $t$-test or Mann-Whitney $U$ test for continuous variables, and by the $\chi^{2}$ test or Fisher's exact test for categorial variables. Cumulative OS curves were determined using Kaplan-Meier analysis and compared with the log-rank test. Univariate and multivariate analyses with the Cox proportional hazards regression model were used to identify independent risk factors for survival, as well as to estimate the respective hazard ratio (HR) and $95 \%$ confidence interval $(\mathrm{Cl})$ values for the various factors. Differences were considered significant at $p<0.05$. All calculations were performed using SPSS version 26.0 software (SPSS, Inc., Chicago, IL, USA).

\section{Results}

\section{Patient characteristics}

A total of 112 patient records with sufficient information and follow-up data were included in the final analysis. Patient characteristics are summarized in Table 1. The median age was 69.5 years (range, 3787 years) and $75 \%$ of the patients were male. Eighty-one patients (72.3\%) had ECOG PS 0 or 1 . The median OS time of all patients was 9.77 months (range, 0.33-69.37 months). Intestinal type histology was observed in 32 patients (28.6\%). Thirty patients (26.8\%) had liver metastasis and $42(37.5 \%)$ had peritoneal seeding. Twenty-one (18.8\%) patients had undergone gastrectomy. The median body mass index of the patients was $21.13 \mathrm{~kg} / \mathrm{m}^{2}$ (range, 13.42-29.83), and the median NLR and PLR were 3.22 (range, 1.15-20.32) and 208.9 (range, 15.1-990.64), respectively. GPS was 0 in 43 patients (38.4\%), 1 in 38 patients (33.9\%), and 2 in 31 patients (27.7\%). With respect to group differences, PLR was significantly higher in the $Y$ group than in the $E$ group (Table 1). 
Table 1

Patient characteristics

\begin{tabular}{|c|c|c|c|c|}
\hline & All patients & $\begin{array}{l}\text { Young group }(n= \\
56)\end{array}$ & $\begin{array}{l}\text { Elderly group }(\mathrm{n}= \\
56)\end{array}$ & $p$-value \\
\hline Age (years) & $69.5(37-87)$ & $62(37-69)$ & $75(70-87)$ & $<0.01$ \\
\hline \multicolumn{5}{|l|}{ Gender (n) } \\
\hline Male & 84 & 40 & 44 & \multirow[t]{2}{*}{0.383} \\
\hline Female & 28 & 16 & 12 & \\
\hline \multicolumn{5}{|l|}{ PS score (n) } \\
\hline 0 & 44 & 20 & 24 & \multirow[t]{3}{*}{0.611} \\
\hline 1 & 43 & 24 & 19 & \\
\hline 2 & 25 & 12 & 13 & \\
\hline $\begin{array}{l}\text { OS (months), median } \\
\text { (range) }\end{array}$ & $9.77(0.33-69.37)$ & $11.9(0.33-40.43)$ & $9.3(0.9-69.37)$ & 0.459 \\
\hline \multicolumn{5}{|l|}{ Histological type (n) } \\
\hline Intestinal type & 32 & 14 & 18 & \multirow[t]{2}{*}{0.446} \\
\hline Mixed/diffuse type & 79 & 41 & 38 & \\
\hline Liver metastasis (n) & 30 & 14 & 16 & 0.67 \\
\hline Peritoneal seeding $(\mathrm{n})$ & 42 & 25 & 17 & 0.118 \\
\hline Gastrectomy (n) & 21 & 9 & 21 & 0.468 \\
\hline BMI, median (range) & $21.13(13.4-29.82)$ & $\begin{array}{l}20.41(13.42- \\
29.83)\end{array}$ & $\begin{array}{l}21.45(14.95- \\
27.78)\end{array}$ & 0.74 \\
\hline CEA, median (range) & $4(0.3-8143)$ & $3.35(0.3-1714)$ & $5.15(0.6-8143)$ & 0.273 \\
\hline $\begin{array}{l}\text { CA19-9, median } \\
\text { (range) }\end{array}$ & $15.1(0-8515)$ & $9.75(0-5104)$ & $15.2(1.5-8515)$ & 0.488 \\
\hline NLR, median (range) & $3.22(1.15-20.32)$ & $3.66(1.15-20.32)$ & $2.77(1.23-10.17)$ & 0.62 \\
\hline PLR, median (range) & $\begin{array}{l}208.89(16.942- \\
990.63)\end{array}$ & $\begin{array}{l}243.67(47.91- \\
990.63)\end{array}$ & $\begin{array}{l}172.63(16.94- \\
542.85)\end{array}$ & $<0.01$ \\
\hline GPS score & & & & \\
\hline
\end{tabular}

Abbreviations: PS, performance status; OS, overall survival; BMI, body mass index; CEA, carcinoembryonic antigen; CA19-9, carbohydrate antigen 19-9; NLR, neutrophil-lymphocyte ratio; PLR, platelet-lymphocyte ratio; GPS, Glasgow prognostic score. 


\begin{tabular}{|lllll|}
\hline & All patients & $\begin{array}{l}\text { Young group }(\mathbf{n}= \\
\mathbf{5 6})\end{array}$ & $\begin{array}{l}\text { Elderly group }(\mathbf{n}= \\
\mathbf{5 6})\end{array}$ & $p$-value \\
\hline 0 & 43 & 23 & 20 & 0.485 \\
1 & 38 & 26 & 22 & \\
2 & 31 & 27 & 14 & \\
\hline $\begin{array}{l}\text { Abbreviations: PS, performance status; OS, overall survival; BMI, body mass index; CEA, } \\
\text { carcinoembryonic antigen; CA19-9, carbohydrate antigen 19-9; NLR, neutrophil-lymphocyte ratio; } \\
\text { PLR, platelet-lymphocyte ratio; GPS, Glasgow prognostic score. }\end{array}$ & \\
\hline
\end{tabular}

After a median follow-up of 9.77 months (range, 0.33-69.37 months), 71 (63.4\%) patients did not survive. Results of Kaplan-Meier curve analysis and the log-rank test showed that, in the Y group, NLR and GPS were significantly associated with OS ( $p=0.002, p=0.009$, respectively), whereas PLR was not $(p=0.296)$ (Fig. 1). Similarly, in the E group, NLR and GPS were significantly associated with OS ( $p<$ $0.001, p=0.034$, respectively), but PLR was not $(p=0.346)$ (Fig. 2$)$.

Univariate analysis of OS indicated that poor PS (HR: 2.64, 95\% Cl: 1.11-6.3, $p=0.029)$, histological diffuse/mixed type (HR: 2.18, 95\% Cl: 1.05-4.52, $p=0.038$ ), peritoneal seeding (HR: $2.33,95 \% \mathrm{Cl}: 1.23-$ $4.42, p=0.01$ ), high NLR (HR: $2.64,95 \% \mathrm{Cl}: 1.38-5.03, p=0.003$ ), and high GPS (HR: $2.29,95 \% \mathrm{Cl}: 1.21-$ $4.35, p=0.011$ ) were significant prognostic factors in the $Y$ group. Further, multivariate analysis demonstrated that poor PS was an independent prognostic factor for OS in the Y group (HR: $2.56,95 \% \mathrm{Cl}$ : $1.02-6.43, p=0.045$ ) (Table 2). Univariate analysis of OS of the E group indicated that poor PS (HR: 3.45 , $95 \% \mathrm{Cl}: 1.53-7.8, p=0.003$ ), high NLR (HR: $4.73,95 \% \mathrm{Cl}: 2.08-10.78, p=0.001)$, and high GPS (HR: 2.46 , $95 \% \mathrm{Cl}: 1.04-5.79, p=0.0028)$ were significant prognostic factors. Further, multivariate analysis demonstrated that a high NLR was an independent prognostic factor for OS in the E group (HR: 4.22, 95\% Cl: $1.69-10.56, p=0.002$; Table 3 ). In summary, the independent prognostic factor for OS in the $Y$ group was PS and that in E group was NLR. 
Table 2

Univariate and multivariate analyses of overall survival in the young group.

\begin{tabular}{|c|c|c|c|c|}
\hline \multicolumn{3}{|l|}{ Univariate } & \multicolumn{2}{|l|}{ Multivariate } \\
\hline Variable & $\mathrm{HR}(95 \% \mathrm{Cl})$ & $p$-value & $\mathrm{HR}(95 \% \mathrm{Cl})$ & $p$-value \\
\hline \multicolumn{5}{|l|}{ Gender } \\
\hline Male (reference) & 1 & 0.769 & & \\
\hline Female & $1.11(0.57-2.15)$ & & & \\
\hline \multicolumn{5}{|l|}{ PS score } \\
\hline 0 or 1 (reference) & 1 & 0.029 & $2.56(1.02-6.43)$ & 0.045 \\
\hline 2 & $2.64(1.11-6.3)$ & & & \\
\hline \multicolumn{5}{|l|}{ Histological type } \\
\hline Intestinal type (reference) & 1 & 0.038 & 1 & 0.164 \\
\hline Mixed/diffuse type & $2.18(1.05-4.52)$ & & $1.81(0.79-4.16)$ & \\
\hline \multicolumn{5}{|l|}{ Liver metastasis } \\
\hline No (reference) & 1 & 0.249 & & \\
\hline Yes & $1.53(0.74-3.16)$ & & & \\
\hline \multicolumn{5}{|l|}{ Peritoneal seeding } \\
\hline No (reference) & 1 & 0.01 & 1 & 0.365 \\
\hline Yes & $2.33(1.23-4.42)$ & & $1.42(0.66-3.05)$ & \\
\hline \multicolumn{5}{|l|}{ Gastrectomy } \\
\hline No (reference) & 1 & 0.848 & & \\
\hline Yes & $1.08(0.48-2.47)$ & & & \\
\hline \multicolumn{5}{|l|}{ PPI } \\
\hline No (reference) & 1 & 0.618 & & \\
\hline Yes & $1.17(0.63-2.2)$ & & & \\
\hline \multicolumn{5}{|l|}{ BMI } \\
\hline$\geq 18.5,<25$ (reference) & 1 & 0.451 & & \\
\hline$<18.5, \geq 25$ & $0.79(0.42-1.48)$ & & & \\
\hline
\end{tabular}

Abbreviations: BMI, body mass index; CA19-9, carbohydrate antigen 19 - 9; CEA, carcinoembryonic antigen; GPS, Glasgow prognostic score; OS, overall survival; NLR, neutrophil-lymphocyte ratio; PLR, platelet-lymphocyte ratio; PPI, proton pump inhibitor; PS, performance status. 


\begin{tabular}{|c|c|c|c|c|}
\hline \multicolumn{3}{|l|}{ Univariate } & \multicolumn{2}{|l|}{ Multivariate } \\
\hline \multicolumn{5}{|l|}{ NLR } \\
\hline$<4$ (reference) & 1 & 0.003 & 1 & 0.153 \\
\hline$>4$ & $2.64(1.38-5.03)$ & & $1.91(0.79-4.65)$ & \\
\hline \multicolumn{5}{|l|}{ PLR } \\
\hline$<150$ (reference) & 1 & 0.3 & & \\
\hline$>150$ & $1.46(0.71-3.01)$ & & & \\
\hline \multicolumn{5}{|l|}{ GPS } \\
\hline 0, 1 (reference) & 1 & 0.011 & & \\
\hline 2 & $2.29(1.21-4.35)$ & & & \\
\hline \multicolumn{5}{|l|}{ CEA } \\
\hline$\leq 5$ (reference) & 1 & 0.299 & & \\
\hline$>5$ & $0.71(0.37-1.36)$ & & & \\
\hline \multicolumn{5}{|l|}{ CA19-9 } \\
\hline$\leq 37$ (reference) & 1 & 0.092 & 1 & 0.469 \\
\hline$>37$ & $1.73(0.92-3.27)$ & & $1.31(0.63-2.74)$ & \\
\hline
\end{tabular}


Table 3

Univariate and multivariate analyses of overall survival in the elderly group.

\section{Univariate}

Variable

Gender

Male (reference)

Female

PS

0 or 1 (reference)

2

Histological type

Intestinal type (reference)

Mixed/diffuse type

Liver metastasis

No (reference)

Yes

1

$1.05(0.48-2.26)$

$3.45(1.53-7.80)$

1

$1.18(0.65-2.16)$

\section{Multivariate}

$\mathrm{HR}(95 \% \mathrm{Cl})$

$p$-value

$\mathrm{HR}(95 \% \mathrm{Cl})$

$p$-value
$1 \quad 0.854$

$1.08(0.47-2.47)$

\section{Peritoneal seeding}

No (reference) 1

0.286

Yes

$1.53(0.7-3.36)$

Gastrectomy

No (reference) 1

0.003

$2.22(0.74-6.65)$

0.153

0.593

Yes

$0.71(0.3-1.68)$

PPI

No (reference)

1

0.053

$2.02(0.81-5.04)$

0.131

Yes

$2.25(0.99-5.11)$

$\mathrm{BMI}$

$\geq 18.5,<25$ (reference)

1

0.277

$<18.5, \geq 25$

$0.65(0.3-1.41)$

Abbreviations: BMI, body mass index; CA19-9, carbohydrate antigen 19 - 9; CEA, carcinoembryonic antigen; GPS, Glasgow prognostic score; OS, overall survival; NLR, neutrophil-lymphocyte ratio; PLR, platelet-lymphocyte ratio; PPI, proton pump inhibitor; PS, performance status. 


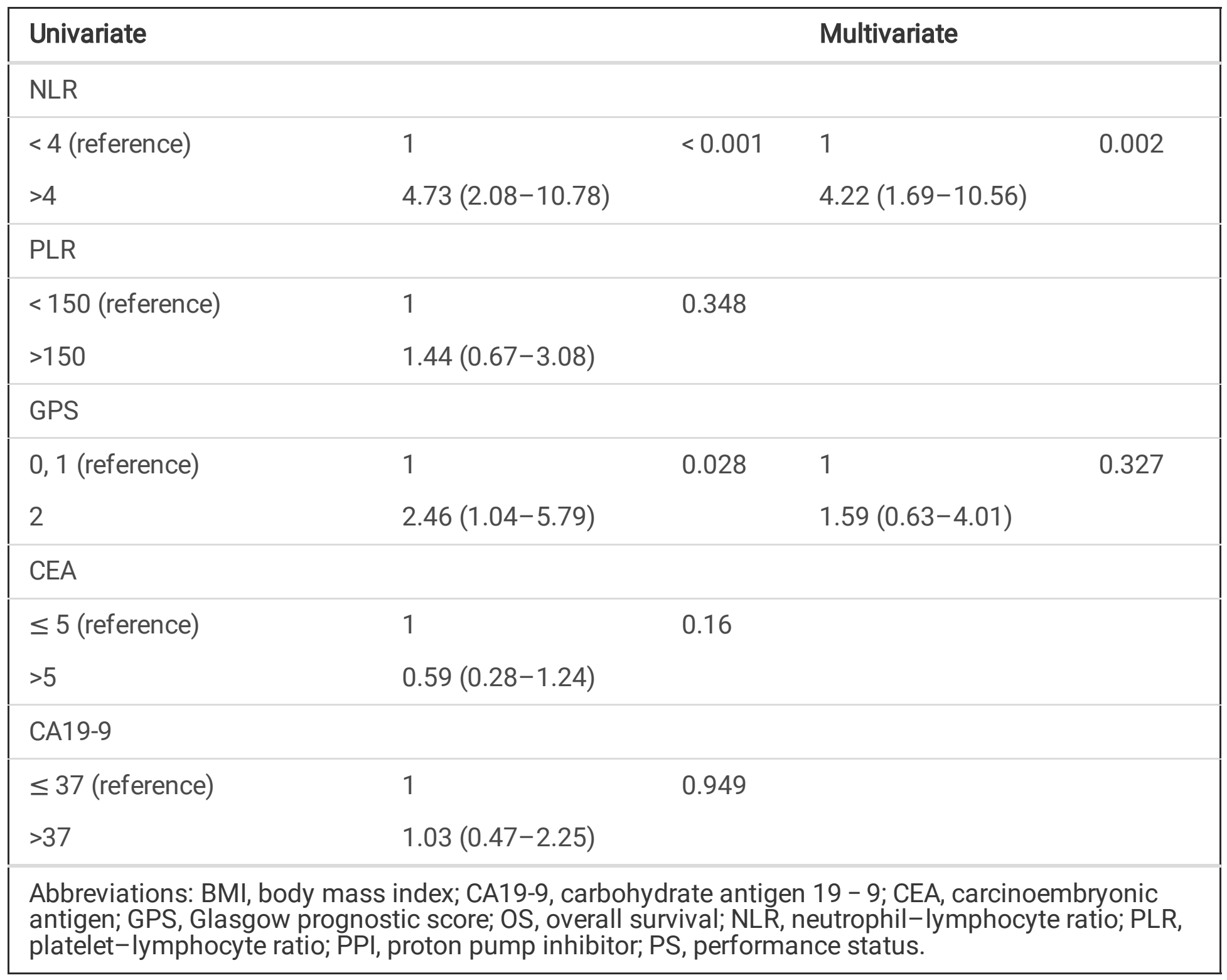

\section{Discussion}

In this study, we investigated the prognostic factors for young and elderly patients with recurrent and unresectable GC. In the Y group, poor PS was an independent factor for a short OS, whereas NLR was the independent prognostic factor in the E group.

Among oncologists, PS is considered an important tool to determine the general conditions of patients. Almost all physicians refer to the PS when considering whether a patient is eligible for treatment or participation in clinical trials. Poor PS has been reported as a predictor of a poor clinical outcome, such as increased adverse events and decreased treatment efficacy in patients receiving chemotherapy [1517]. However, PS may not be sufficient when assessing the elderly for chemotherapy [18] due to the high heterogeneity of this population, including medical history, organ function, and nutritional status [19]. Indeed, in this study, NLR rather than PS was an independent prognostic factor for OS of the E group. 
NLR is useful for predicting clinical outcomes in several studies including both young and elderly patients with cancer $[13,20,21]$. A high NLR indicates an increased neutrophil count and/or a decreased lymphocyte count, as well as relative lymphopenia. The relationship between NLR and prognosis of patients with cancer is still not well understood. However, both neutrophils and lymphocytes are considered to be related to cancer prognosis. First, neutrophils play significant roles in the process of cancer progression, including tumor initiation, growth, proliferation, or metastatic stage [22, 23]. Furthermore, neutrophilia inhibits the cytotoxic activity of lymphocytes such as T cells and natural killer cells and facilitates the extravasation of tumor cells [24]. By contrast, lymphocytes play an important role in the immune system against cancers. Peripheral low lymphocyte counts have been associated with a poor outcome in various cancers [25-27] and were related with lymphatic invasion and recurrence of lung cancer [28]. Lymphocytes play a crucial role in the anti-tumor immune response. Accordingly, reduction in the lymphocyte count reduces the anti-tumor effect of the immune system, resulting in accelerated tumor occurrence and development [29].

This background clearly demonstrates an association of NLR with the cancer immune environment; consequently, NLR is considered to be related with the clinical outcome. The present finding that NLR may be a specific prognostic factor of OS in elderly patients with GC indicates that NLR might not only reflect the tumor environment but may also be associated with host frailty [30,31]. Frailty is a syndrome affecting physiologic reserves across multiple organ systems and has been identified as a poor prognostic factor in geriatric oncology $[32,33]$.

Nishijima et al. [31] reported a significant association between NLR and frailty only in the geriatric population, which supports our findings. Nevertheless, the mechanism underlying the association between NLR and frailty is uncertain. Gilmore et al. [34] reported that chronic low-grade inflammation may be involved in the relationship between NLR and frailty.

In summary, our results suggest that NLR is a useful prognostic factor by reflecting not only the tumor immune environment but also frailty in elderly patients with cancer. By contrast, PS emerged as a useful marker for predicting survival in younger patients, which may not be a significant prognostic factor in elderly patients because of its reduced reliability for this population, as suggested in previous reports.

The present study had various limitations. First, as the data were collected from a single center, we could not entirely avoid selection bias associated with patients and chemotherapy regimens. Second, we could not completely exclude the possibility of complications such as subclinical infection that might affect the prognostic values of biomarkers. This limitation might more strongly affect the results in the E group due to the greater complexity of their comorbidities. Third, the most significant limitation of this study was the low number of patients investigated; thus, validation will be required via prospective studies with a larger cohort. The relatively small number of patients and events in our cohort did not allow for comprehensive multivariable analyses and precluded making definitive conclusions. However, the correlation of high NLR and poor prognosis of the E group was highly statistically significant and also seems to be clinically meaningful. 


\section{Conclusion}

Poor PS was an independent marker of poor prognosis in the Y group, whereas high NLR was an independent marker of OS in the E group. Thus, NLR could be a specific biomarker to predict the OS of elderly patients with unresectable GC, offering a cost-effective prognostic biomarker. Further prospective studies with sufficient sample sizes are needed to validate our results.

\section{Abbreviations}

$\mathrm{Cl}$, confidence interval; E group, elderly group; ECOG, Eastern Cooperative Oncology Group; GC, gastric cancer; GPS, Glasgow prognostic score; HR, hazard ratio; IL-6, interleukin-6; NLR, neutrophil-lymphocyte ratio; OS, overall survival; PLR, platelet-lymphocyte ratio; PS, performance status; Y group, young group.

\section{Declarations}

\section{Ethics approval and consent to participate}

This study was approved by the institutional review boards of Tokyo Medical University (T2020-0442) and conformed to the provisions of the Declaration of Helsinki. The institutional review boards of Tokyo Medical University approved that the informed consent requirement was waived due to the study's observational retrospective design, with an opt-out opportunity provided at the institution's website.

\section{Consent for publication}

Not applicable.

\section{Availability of data and materials}

The datasets used and/or analyzed during the current study are available from the corresponding author on reasonable request.

\section{Competing interests}

The authors declare that they have no competing interests.

\section{Funding}

No funding was acquired for this study.

\section{Authors' contributions}

YY and AS designed the study, performed the statistical analysis, and drafted the manuscript. YS, TK and $\mathrm{KI}$ collected the clinical data and revised the manuscript critically. AT and IT critically reviewed the manuscript. All authors read and approved the final manuscript. 
Acknowledgements

Not applicable.

\section{References}

1. Torre LA, Bray F, Siegel RL, Ferlay J, Lortet-Tieulent J, Jemal A. Global cancer statistics, 2012. CA Cancer J Clin. 2015;65:87-108.

2. Statistics and Information Department Minister's Secretariat. Vital Statistics of Japan. Tokyo, Japan, Ministry of Health and Welfare of Japan, 2000.

3. Saito H, Osaki T, Murakami D, Sakamoto T, Kanaji S, Tatebe S, et al. Effect of age on prognosis in patients with gastric cancer. ANZ J Surg. 2006;76:458-61.

4. Kodaira M, Takahashi S, Yamada S, Ueda K, Mishima Y, Takeuchi K, et al. Bone metastasis and poor performance status are prognostic factors for survival of carcinoma of unknown primary site in patients treated with systematic chemotherapy. Ann Oncol. 2010;21:1163-7.

5. Foote M. The importance of planned dose of chemotherapy on time: do we need to change our clinical practice?Oncologist. 1998;3:365-8.

6. Balducci L, Beghe C. The application of the principles of geriatrics to the management of the older person with cancer. Crit Rev Oncol Hematol. 2000;35:147-54.

7. Mantovani A, Allavena P, Sica A, Balkwill F. Cancer-related inflammation. Nature. 2008;454:436-44.

8. Hussain SP, Harris CC. Inflammation and cancer: an ancient link with novel potentials. Int J Cancer. 2007; 121:2373-80.

9. Gomez D, Morris-Stiff G, Toogood GJ, Lodge JPA, Prasad KR. Impact of systemic inflammation on outcome following resection for intrahepatic cholangiocarcinoma. J Surg Oncol. 2008;97:513-8.

10. Bhatti I, Peacock O, Lloyd G, Larvin M, Hall RI. Preoperative hematologic markers as independent predictors of prognosis in resected pancreatic ductal adenocarcinoma: neutrophil-lymphocyte versus platelet-lymphocyte ratio. Am J Surg. 2010; 200:197-203.

11. Feng JF, Huang Y, Chen QX. Preoperative platelet lymphocyte ratio (PLR) is superior to neutrophil lymphocyte ratio (NLR) as a predictive factor in patients with esophageal squamous cell carcinoma. World J Surg Oncol. 2014; 12:58.

12. Wang DS, Ren C, Qiu MZ, Luo HY, Wang ZQ, Zhang DS, et al. Comparison of the prognostic value of various preoperative inflammation-based factors in patients with stage III gastric cancer. Tumor Biol. 2012;33:749-56.

13. Shimada H, Takiguchi N, Kainuma O, Soda H, Ikeda A, Cho A, et al. High preoperative neutrophillymphocyte ratio predicts poor survival in patients with gastric cancer. Gastric Cancer. 2010;13:1706.

14. Song W, Tian C, Wang K, Zhang RJ, Zou SB. Preoperative platelet lymphocyte ratio as independent predictors of prognosis in pancreatic cancer: A systematic review and meta-analysis. PLoS One. 
2017;12:e0178762.

15. Gajra A, Marr AS, Ganti AK. Management of patients with lung cancer and poor performance status. J Natl Compr Cancer Netw. 2014;12:1015-25.

16. Fiorin de Vasconcellos V, Rcc Bonadio R, Avanço G, Negrão MV, Pimenta Riechelmann R. Inpatient palliative chemotherapy is associated with high mortality and aggressive end-of-life care in patients with advanced solid tumors and poor performance status. BMC Palliat Care. 2019;18:42.

17. da Rocha IMG, Marcadenti A, de Medeiros GOC, Bezerra RA, Rego JFM, Gonzalez MC, Fayh APT. Is cachexia associated with chemotherapy toxicities in gastrointestinal cancer patients? A prospective study. J Cachexia Sarcopenia Muscle. 2019;10:445-54.

18. Blanquicett C, Cohen JB, Flowers C, Johnson T. The role of the comprehensive geriatric assessment in the evaluation of the older cancer patient. 2019; 14;33:687524.

19. Soto-Perez-de-Celis E,Li D, Yuan Y, Ming Lau Y, Hurria A. Functional versus chronological age: geriatric assessments to guide decision making in older patients with cancer. Lancet Oncol. 2018;19:e305-16.

20. Moon G, Noh H, Cho IJ, Lee JI, Han A. Prediction of late recurrence in patients with breast cancer: elevated neutrophil to lymphocyte ratio (NLR) at 5 years after diagnosis and late recurrence. Breast Cancer. 2020;27:54-61.

21. Liu D, Jin J, Zhang L, Li L, Song J, Li W. The neutrophil to lymphocyte ratio may predict benefit from chemotherapy in lung cancer. Cell Physiol Biochem. 2018;46:1595-1605.

22. Swierczak A, Mouchemore KA, Hamilton JA, Anderson RL. Neutrophils: important contributors to tumor progression and metastasis. Cancer Metastasis Rev. 2015;34:735-51.

23. Coffelt SB, Wellenstein MD, de Visser KE. Neutrophils in cancer: neutral no more. Nat Rev Cancer. 2016;16:431-46.

24. Spiegel A, BrooksMW, Houshyar S, Reinhardt F, ArdolinoM, Fessler E, et al. Neutrophils suppress intraluminal NK cell-mediated tumor cell clearance and enhance extravasation of disseminated carcinoma cells. Cancer Discov. 2016;6:630-49.

25. Blake-Mortimer JS, Sephton SE, Carlson RW, Stites D, Speigel D. Cytotoxic T lymphocyte count and survival time in women with metastatic breast cancer. Breast J. 2004;10:195-9.

26. Fumagalli LA, Vinke J, Hoff W, Ypma E, Brivio Y, Nespoli A. Lymphocyte counts independently predict overall survival in advanced cancer patients: a biomarker for IL-2 immunotherapy. J Immunother. 2003;26:394-402.

27. Fogar P, Sperti C, Basso D, Sanzari MC, Greco E, Davoli C, et al. Decreased total lymphocyte counts in pancreatic cancer: an index of adverse outcome. Pancreas. 2006;32:22-8.

28. Mantovani A, Allavena P, Sica A, Balkwill F. Cancer-related inflammation.2008;454:436-44.

29. Lin EY, Li JF, Gnatovskiy L, Deng Y, Zhu L, Grzesik DA, et al. Macrophages regulate the angiogenic switch in a mouse model of breast cancer. Cancer Res. 
$2006 ; 66: 11238-46$.

30. Hou P, Xue HP, Mao XE, Li YN, Wu LF, Liu YB. Inflammation markers are associated with frailty in elderly patients with coronary heart disease. 2018;10:2636-45.

31. Nishijima TF, Deal AM, Williams GR, Guerard EJ, Nyrop KA, Muss HB. Frailty and inflammatory markers in older adults with cancer. 2017;9:650-64.

32. Leng SX, Xue QL, Tian J, Huang Y, Yeh SH, Fried LP. Associations of neutrophil and monocyte counts with frailty in community-dwelling disabled older women: results from the Women's Health and Aging Studies I. Exp Gerontol. 2009;44:511-16.

33. Collerton J, Martin-Ruiz C, Davies K, Hilkens CM, Isaacs J, Kolenda C, et al. Frailty and the role of inflammation, immunosenescence and cellular ageing in the very old: Cross-sectional findings from the Newcastle 85+ Study. Mech Ageing Dev. 2012;133:456-66.

34. Gilmore N, Mohile S, Lei L, Culakova E, Mohamed M, Magnuson A, et al. The longitudinal relationship between immune cell profiles and frailty in patients with breast cancer receiving chemotherapy.

Breast Cancer Res. 2021;23:19.

\section{Figures}




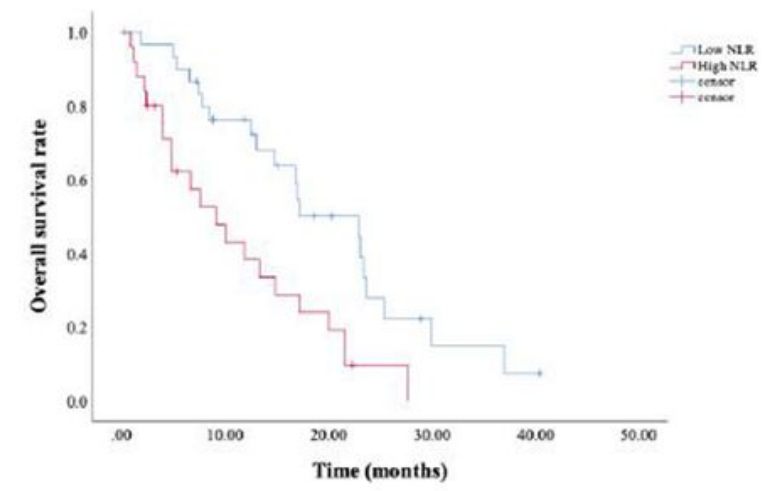

b)

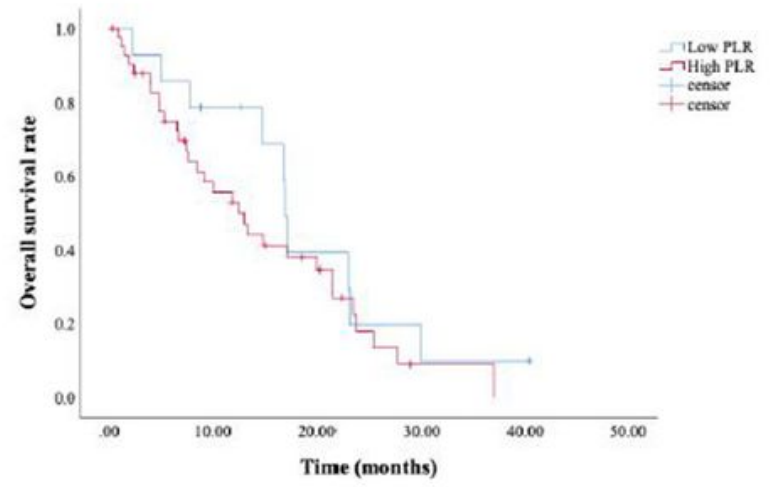

c)

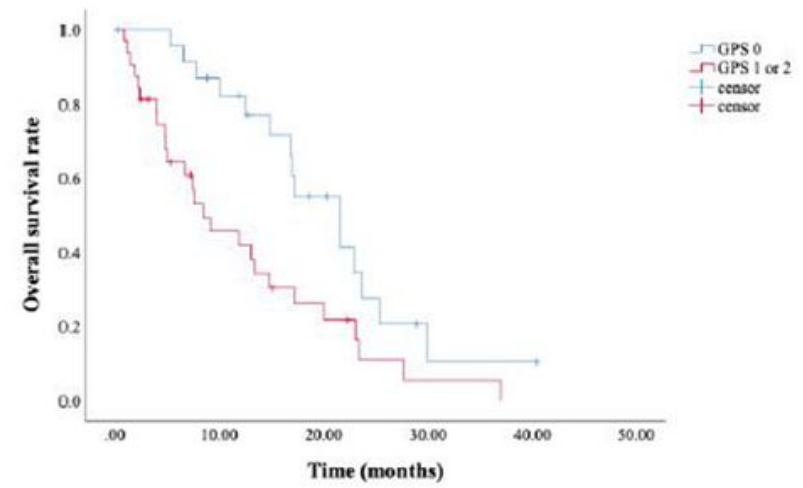

\section{Figure 1}

Kaplan-Meier survival curves for overall survival (OS) associated with inflammation-based scores in the young group. (a) Neutrophil-lymphocyte ratio (NLR). (b) Platelet-lymphocyte ratio (PLR). (c) Glasgow prognostic score (GPS). High NLR and GPS $=1$ or 2 were significantly associated with poor OS $(p=0.002$, $p=0.009$, respectively). 


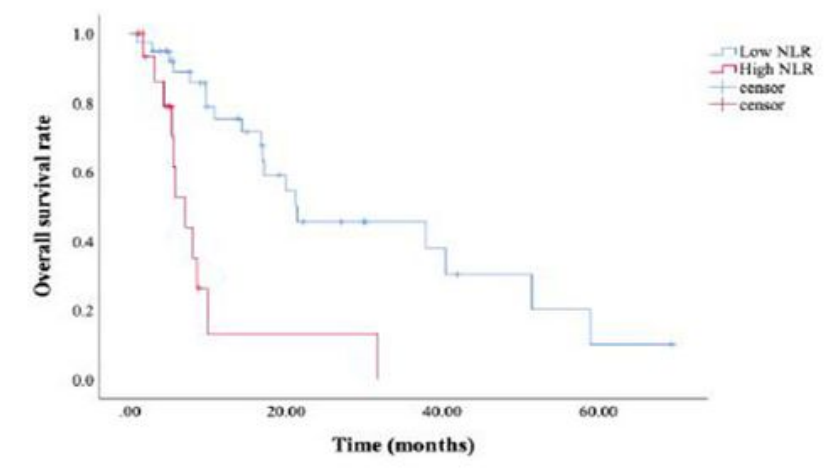

b)

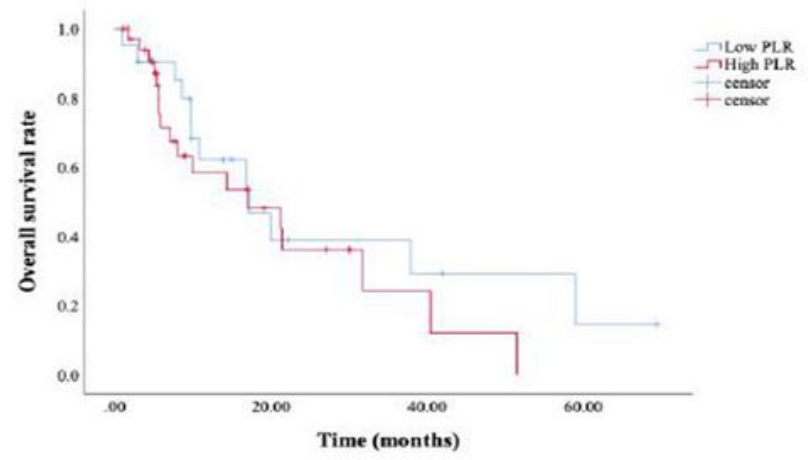

c)

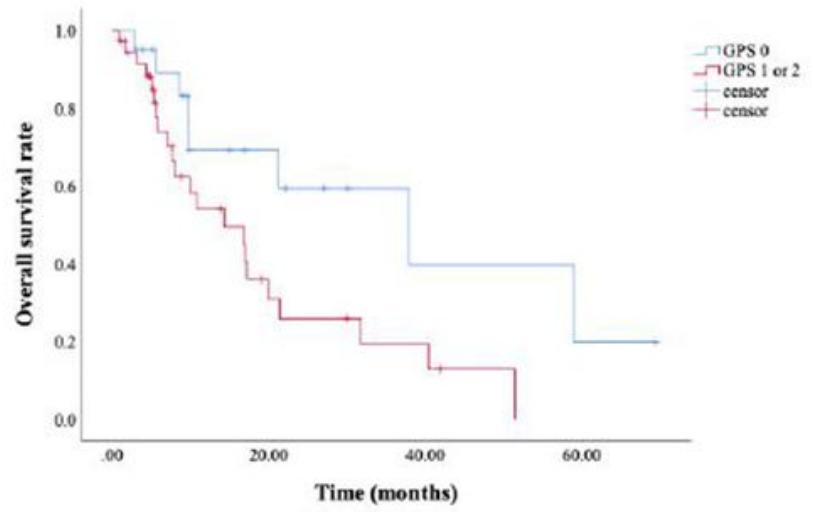

\section{Figure 2}

Kaplan-Meier survival curves for overall survival (OS) associated with inflammation-based scores in the elderly group. (a) Neutrophil-lymphocyte ratio (NLR). (b) Platelet-lymphocyte ratio (PLR). (c) Glasgow prognostic score (GPS). High NLR and GPS $=1$ or 2 were significantly associated with poor OS $(p<0.001$, $p=0.034$, respectively). 